\title{
Insulin induction instigates cell proliferation and metastasis in human colorectal cancer cells
}

\author{
CHI-CHENG LU ${ }^{1,2}$, PEI-YI CHU ${ }^{2}$, SHIH-MIN HSIA ${ }^{1}$, CHI-HAO WU ${ }^{1}$, \\ YU-TANG TUNG ${ }^{1,2}$ and GOW-CHIN YEN ${ }^{2,3}$ \\ ${ }^{1}$ School of Nutrition and Health Sciences, Taipei Medical University, Taipei 110; \\ ${ }^{2}$ Department of Food Science and Biotechnology, National Chung Hsing University, Taichung 402; \\ ${ }^{3}$ Agricultural Biotechnology Center, National Chung Hsing University, Taichung 402, Taiwan, R.O.C.
}

Received September 30, 2016; Accepted December 30, 2016

DOI: $10.3892 /$ ijo.2017.3844

\begin{abstract}
The progression of colorectal cancer has been reported to have a positive correlation with the combination of hyperglycemia and hyperinsulinemia in diabetic patients, leading to a lower survival rate. However, how insulin acts on colorectal cancer remains not well understood. The purpose of this study was to explore the effect of insulin on colon cancer cell proliferation and its underlying molecular signaling as well as the impact of insulin-induced in vitro metastasis. Our results showed that insulin markedly promoted cell proliferation, migration and anchorage-independent growth in human colon cancer HCT-116 cells. Insulin-regulated insulin receptors (IRs) stimulate insulin receptor substrate 1 (IRS-1) and interact with the downstream signals, causing a rise in HCT-116 cell proliferation. Moreover, insulin significantly induced the migration ability of HCT-116 cells. The metastatic ability of matrix metalloproteinase-2 (MMP-2) mRNA and activity was activated by insulin. Overall, insulin-triggered cell proliferation and metastatic effects on colorectal cancer cells are mediated by IRS-1 and downstream molecules and by increasing phosphoinositide 3-kinase (PI3K)/Akt and mitogenactivated protein kinase (MAPK) signaling. Therefore, insulin induction might have the potential to induce colorectal cancer progression in diabetes patients.
\end{abstract}

Correspondence to: Dr Gow-Chin Yen, Department of Food Science and Biotechnology, National Chung Hsing University, 145 Xingda Road, Taichung 40227, Taiwan, R.O.C.

E-mail: gcyen@nchu.edu.tw

Abbreviations: ECM, extracellular matrix; IR, insulin receptor; IRS-1, insulin receptor substrate 1; MAPKs, mitogen-activated protein kinases; MMP-2, matrix metalloproteinase-2; PI3K, phosphoinositide 3-kinase; poly-HEMA, poly(2-hydroxyethyl methacrylate)

Key words: diabetes, insulin, colon cancer, cell proliferation, cell migration

\section{Introduction}

Diabetes mellitus has become one of the major diseases that is hazardous to human health and is caused by the change in lifestyle and western style diet in recent years (1). Diabetes is a systemic disease of metabolic disorders and leads to an increasing number of deaths (2). Poor insulin activity and inadequate insulin secretion can cause carbohydrate metabolism problems, finally resulting in patients developing hyperglycemia and hyperinsulinemia (3). In addition, there is growing evidence that there is a connection between type 2 diabetes and the increased appearance of new tumor cases as shown in retrospective and prospective epidemiological studies $(4,5)$. Patients with type 2 diabetes have a high risk of cancer, and colorectal cancer is the third leading cause of cancer death according to the cancer statistics in Taiwan (6). The principal source of energy upon the glycolysis of glucose has been directly monitored in migrating tumor cells (7). However, in the insulin-free condition, the high blood glucose fails to promote tumor growth due to insulin deficiency $(8,9)$, which might be a mediator in the induction of hyperinsulinemia to increase the factors of cancer progression (10).

Colorectal cancer patients with diabetes have a higher mortality rate than those with type 2 diabetes alone $(11,12)$. In addition, human evidence has also demonstrated that high levels of insulin with an increased risk of colon cancer and increased circulating concentrations of insulin are associated with a higher risk of colonic neoplasia (13). Furthermore, chronic hyperinsulinemia might stimulate insulin receptor (IR) signaling to induce tumor growth in breast and pancreatic cancers $(14,15)$. Currently, there is no available information regarding a link between colorectal cancer and type 2 diabetes in patients, and the molecular mechanism of high insulininduced signaling in colon cancer remains unclear. Herein, we focused on the role of insulin in the proliferation and metastatic effects on human colorectal cancer cells.

We further investigated how the addition of insulin promoted cell proliferation and migration by modifying the expression of IR signaling, the phosphoinositide 3-kinase (PI3K)/Akt/glycogen synthase kinase-3 $\beta$ (GSK3 $\beta$ ) pathway and matrix metalloproteinase-2 (MMP-2) regulation in treated colorectal cancer cells. Therefore, our results confirm a link 
between insulin and colorectal cancer cell progression and clarify how insulin acts as a molecular modulator using a cultured cell model.

\section{Materials and methods}

Chemicals and reagents. Anti- $\beta$-actin antibody, fish gelatin and poly(2-hydroxyethyl methacrylate) (poly-HEMA) were obtained from Sigma-Aldrich (St. Louis, MO, USA). Penicillinstreptomycin solution, insulin, sodium pyruvate, RPMI-1640 medium, trypsin-EDTA and TRI Reagent Solution were purchased from Thermo Fisher Scientific (Waltham, MA, USA). Fetal bovine serum (FBS) was obtained from Biological Industries (Cromwell, CT, USA). Nuclear/Cytosol Fractionation kit and anti-lamin B1 antibody were from BioVision (Mountain View, CA, USA). Anti-IR antibody was obtained from Abcam (Cambridge, UK). Anti-phospho-mTOR (Ser2448), anti-mTOR, anti-cyclin D1, SB203580 (a p38 inhibitor) and wortmannin (a PI3K inhibitor) were from EMD Millipore (Billerica, MA, USA). Antibodies against JNK and p-JNK (Thr183/Tyr185) were obtained from Santa Cruz Biotechnology (Santa Cruz, CA, USA). The other antibodies used in this study were purchased from Cell Signaling Technology (Beverly, MA, USA). Anti-rabbit and anti-mouse secondary horseradish peroxidase (HRP) antibodies were obtained from Bethyl Laboratories (Montgomery, TX, USA). PD98059 (an ERK inhibitor) and SP600125 (a JNK inhibitor) were obtained from Biosource International, Inc. (Camarillo, CA, USA).

Cell culture. Human colorectal carcinoma HCT-116 cell line (BCRC no. 60349) was purchased from the Bioresource Collection and Research Center (BCRC) (Hsinchu, Taiwan). Based on the information of BCRC, the initial origin of this cell line is from male colorectal carcinoma tissue. HCT-116 cells have been shown to express Akt1 and Akt 2 in the absence of Akt3 in insulin-stimulated conditions $(16,17)$. The cells were maintained in RPMI-1640 medium supplemented with $10 \% \mathrm{FBS}, 100 \mu \mathrm{g} / \mathrm{ml}$ penicillin and $100 \mathrm{U} / \mathrm{ml}$ streptomycin at $37^{\circ} \mathrm{C}$ in a humidified atmosphere of $95 \%$ air and $5 \% \mathrm{CO}_{2}$. The culture medium was renewed each day. Cells were subcultured every 3 days with $0.1 \%$ trypsin-EDTA.

Cell viability assay. Cell viability was determined with a trypan blue assay as previously described (18). HCT-116 cells $\left(5 \times 10^{4}\right.$ cells/well $)$ were seeded onto a 24 -well plate in RPMI-1640 medium with $1 \%$ FBS. After a 24 h incubation, pretreatment with or without $20 \mu \mathrm{M}$ of SP600125, PD98059, SB203580 and wortmanin, respectively, for $1 \mathrm{~h}$, and the cells were treated with or without various concentrations $(100$, $150,200,250$ and $300 \mathrm{nM}$ ) of insulin in culture medium with $1 \%$ FBS for $48 \mathrm{~h}$. Cells were harvested and then stained with $0.4 \%$ trypan blue to count the live and dead cells using an Olympus IX71 Inverted System Microscope (Olympus, Tokyo, Japan).

Cell proliferation assay. The 96-well plate was coated with $50 \mu \mathrm{l}$ of $12 \%$ poly-HEMA solution dissolved in $95 \%$ ethanol as described by previous studies $(19,20)$. HCT-116 cells $\left(5 \times 10^{3}\right.$ cells/well) were seeded onto 96 -well plates coated with or without poly-HEMA. After $24 \mathrm{~h}$ of incubation, the cells were treated with various concentrations $(100,150$ and $200 \mathrm{nM}$ ) of insulin in RPMI-1640 medium with 1\% FBS and further incubated for $48 \mathrm{~h}$. CellTiter 96 AQueous One Solution Cell Proliferation Assay kit (Promega, Madison, WI, USA) was used, and the absorbance at $490 \mathrm{~nm}$ was recorded with a FLUOstar galaxy spectrophotometer (BMG Labtech, Ortenberg, Germany).

Western blotting. The treated HCT-116 cells were harvested and lysed in RIPA Lysis Buffer (EMD Millipore). Nuclear and cytosolic fractions were prepared utilizing the Nuclear/ Cytosol Fractionation kit (BioVision) as specified in the manufacturer's protocol. The protein concentration was detected using the Bio-Rad protein assay (Bio-Rad Laboratories, Hercules, CA, USA), and then the lysate was mixed with protein loading dye and boiled, as previously described (21). The sample $(50 \mu \mathrm{g})$ was subjected to sodium dodecyl sulfate (SDS)-polyacrylamide gel electrophoresis, and the separated protein was transferred onto cellulose nitrate membrane (Sartorius Stedim Biotech GmbH, Goettingen, Germany). Each membrane was immunoblotted directly against an appropriate antibody [anti-IR, anti-IRS-1, anti-phospho-PI3K, anti-PI3K, anti-phospho-Akt (Ser473), anti-Akt, anti-phospho-mTOR (Ser2448), anti-mTOR, anti-phospho-GSK3 $\beta$ (Ser9), antiGSK3 $\beta$, anti-p53, anti-cyclin D1, anti-c-Myc, anti-heat shock protein 27 (HSP27), anti-phospho-ERK1/2 (Thr202/Tyr204), anti-ERK1/2, anti-phospho-JNK (Thr183/Tyr185), anti-JNK, anti-phospho-p38 (Thr180/Tyr182) and anti-p38] overnight and then further incubated with HRP-conjugated secondary antibody (1:10000 dilutions). The protein levels were normalized to lamin B1 or $\beta$-actin. The signal was analyzed using Immobilon Western Chemiluminescent HRP Substrate (EMD Millipore), and the signal intensity was quantified using VisionWorks LS Image Acquisition and Analysis Software (version 6.3.3, UVP, Upland, CA, USA).

Wound healing assay. The Culture-Insert 2 Well (Ibidi, Martinsried, Germany) was placed onto a 12-well plate, and HCT-116 cells ( $7 \times 10^{4}$ cells/well) were seeded into the cultureinsert. After $12 \mathrm{~h}$ of incubation, the culture-insert was removed, and cells were treated with various concentrations (100, 150 and $200 \mathrm{nM}$ ) of insulin in RPMI-1640 medium with 1\% FBS and further incubated for 24, 48 and $72 \mathrm{~h}$. Photographs of the wound adjacent to reference lines scraped on the bottom of the plate were taken using an Olympus IX71 Inverted System Microscope. The cells were examined and quantified to measure relative to a control well.

Transwell migration assay. Cell migration was determined with a Transwell migration assay. Transwell polycarbonate membrane cell culture inserts (Corning, Lowell, MA, USA) were placed onto a 24-well plate, and HCT-116 cells $\left(1 \times 10^{5}\right.$ cells/well $)$ were treated at various concentrations $(100,150$ and $200 \mathrm{nM})$ of insulin in serum-free RPMI-1640 medium. A serum-containing medium $(650 \mu \mathrm{l})$ was added to the lower chambers. After incubating for $48 \mathrm{~h}$, filter inserts were removed from the wells, and the cells that migrated through the membrane were fixed with methanol and stained with crystal violet, as previously described (22). Photographs were taken using an Olympus Power IX71 microscope, and 

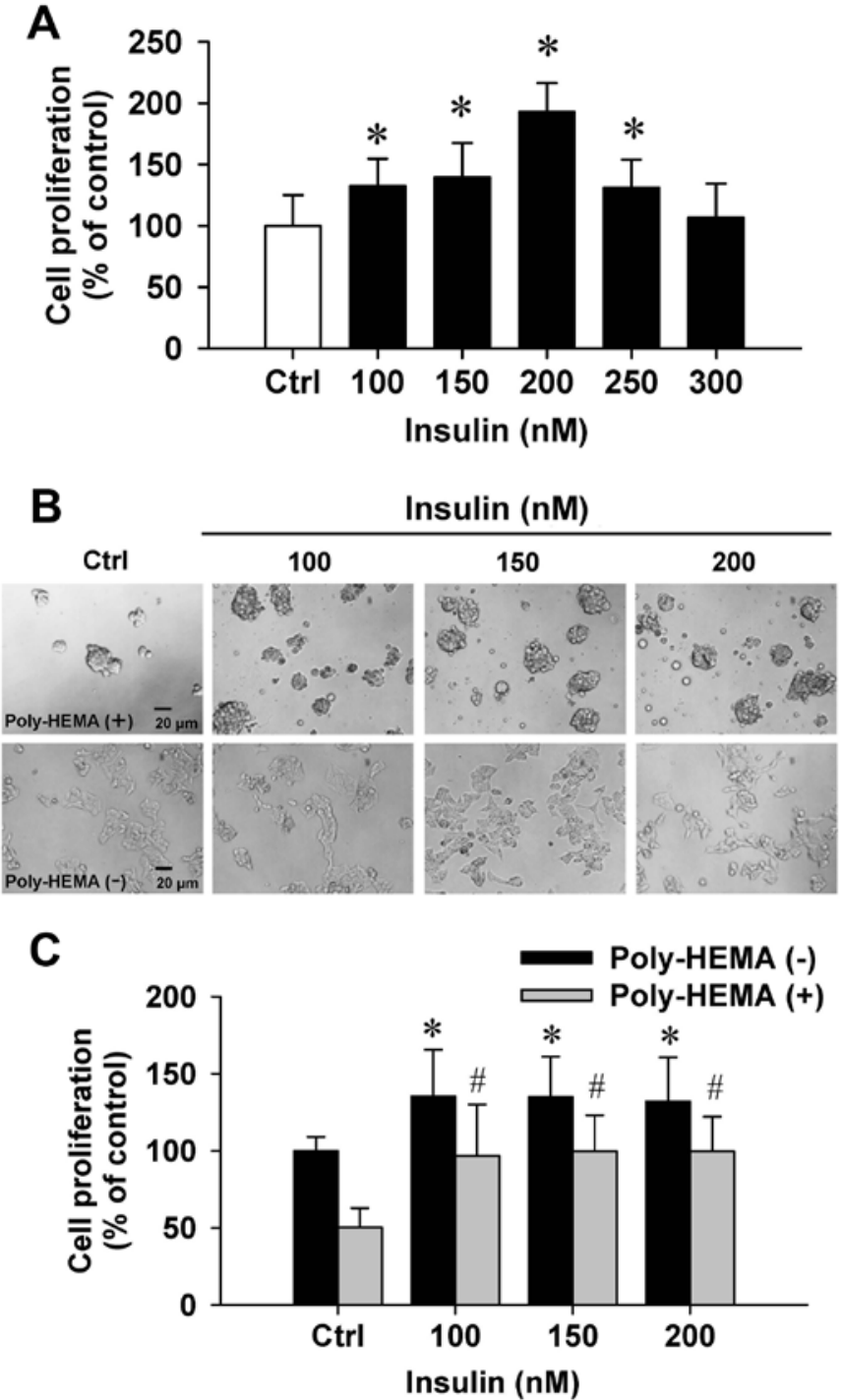

Figure 1. Effect of insulin on HCT-116 cell proliferation in vitro. Cells were treated with or without 100, 150, 200, 250 or $300 \mathrm{nM}$ insulin for $48 \mathrm{~h}$. (A) Cell proliferation was determined by the trypan blue exclusion method. Cells were added to wells precoated with or without poly-HEMA and then were incubated with the indicated concentrations of insulin for $48 \mathrm{~h}$. (B) Cells were observed and photographed under a phase-contract microscope (scale bar=20 $\mu \mathrm{m}$ ). (C) Quantification of cell proliferation from coated and uncoated plates was performed as described in Materials and methods. The data are expressed as the mean $\pm \mathrm{SD}(\mathrm{n}=3) .{ }^{*} \mathrm{P}<0.05$ vs. untreated control; ${ }^{\#} \mathrm{P}<0.05$ vs. untreated control in the uncoated poly-HEMA plate.

the migrated cells were quantified by ImageJ 1.47 program for Windows from the National Institute of Health (NIH) (Bethesda, MD, USA).

Reverse transcription PCR. HCT-116 cells were treated with 100,150 and $200 \mathrm{nM}$ of insulin for $48 \mathrm{~h}$ before being collected to extract total RNA using TRIzol Reagent (Thermo Fisher Scientific), as previously described (21) and reverse transcribed to produce cDNA using the SuperScript III First-Strand Synthesis SuperMix for qRT-PCR kit (Thermo Fisher Scientific) according to the manufacturer's protocols. The primers used for PCR to amplify the target genes were as follows: MMP-2, forward: TACACCGGGCCTGGAGAAC TAG, reverse: GCTCTGAGGGTTGGTGGGATTG; MMP-9, forward: CTGGAGGTTCGACGTGAAGG, reverse: AGG
TCACGTAGCCCACTTGG; 18S rRNA, forward: GTAACC CGTTGAACCCCATT, reverse: CCATCCAATCGGTAGTA GCG. The PCR products were separated by electrophoresis on a $1.5 \%$ agarose gel, and the DNA bands were detected using the SYBR Safe DNA gel stain (Thermo Fisher Scientific). The gel was then photographed using a BioDoc-It system (UVP). The results were expressed as the ratio of each DNA signal relative to the corresponding $18 \mathrm{~S}$ rRNA signal.

Gelatin zymography. HCT-116 cells $\left(1 \times 10^{5}\right.$ cells/well) were seeded onto 24-well plates in serum-free RPMI-1640 medium and thereafter treated with various concentrations (100, 150 and $200 \mathrm{nM}$ ) of insulin for $48 \mathrm{~h}$. Thereafter, the conditioned media were collected, and the unboiled sample was separated by electrophoresis on $8 \%$ SDS-polyacrylamide gels containing $0.1 \%$ gelatin (Sigma-Aldrich). After electrophoresis, the gels were washed twice in washing buffer and then incubated in reaction buffer at $37^{\circ} \mathrm{C}$ for $16 \mathrm{~h}$ as previously described $(22,23)$. Bands corresponding to activity were visualized by negative staining using Coomassie Brilliant Blue R-250 (Bio-Rad Laboratories), and quantitative data were analyzed utilizing VisionWorks LS Image Acquisition and Analysis Software (version 6.3.3, UVP).

Statistical analysis. The data are expressed as the mean \pm SD of three independent experiments. Kruscal-Wallis H test was subsequently followed up with Bonferroni method to evaluate the statistical significance. P-value $<0.05$ was considered to indicate a statistically significant difference.

\section{Results}

Insulin induces human colorectal carcinoma HCT-116 cell proliferation in vitro. To examine the effects of insulin on cytotoxicity, the trypan blue method was performed. Insulin at 100-300 $\mathrm{nM}$ showed no cytotoxic influence on the number of dye-excluding HCT-116 cells (Fig. 1A). Importantly, insulin at $100-250 \mathrm{nM}$ significantly increased cell proliferation (Fig. 1A). Next, the effect of cell proliferation on insulininduced cells was examined by the poly-HEMA-coated plate assay. Our data demonstrated that cells grew in aggregates and showed sphere formation in a poly-HEMA-precoated plates (Fig. 1B, top panel). A comparison of adherent and aggregated cells revealed that cells floated in the media. In addition, HCT-116 cell growth was notably increased by insulin in coated and uncoated poly-HEMA samples compared with their untreated counterparts (Fig. 1C). Thus, these data indicated that insulin effectively promoted HCT-116 cell growth and proliferation in vitro.

Insulin modulates the IR pathway via PI3K/Akt signaling in HCT-116 cells. Cells were exposed to various concentrations of insulin, and the protein levels of IR and IRS-1 were then assessed by immunoblotting analysis. Both the IR and IRS-1 levels were increased after treatment with insulin (Fig. 2A). Moreover, treatment with insulin induced the phosphorylation of PI3K and Akt (Ser473) in HCT-116 cells, but no effect appeared in the protein levels of PI3K and Akt in insulintreated cells (Fig. 2B). These results suggest that insulin induced the IR signal by regulating the PI3K/Akt pathway, 
A

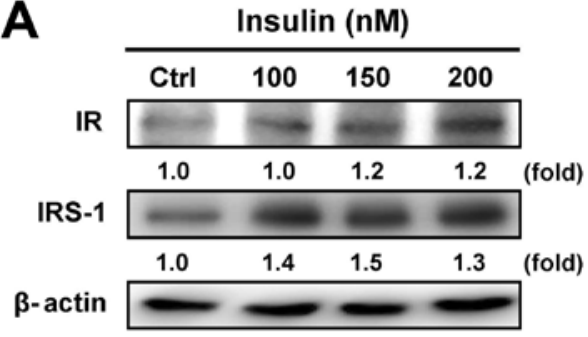

B

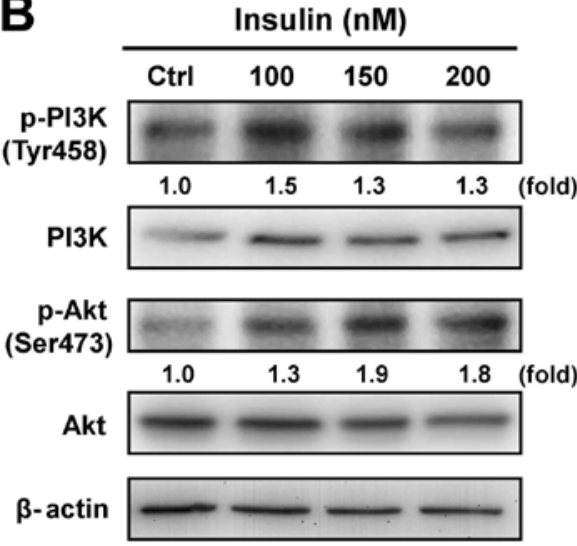

Figure 2. Effect of insulin on the insulin receptor (IR) pathway and PI3K Akt signaling in HCT-116 cells. Cells were exposed to 100,150 and $200 \mathrm{nM}$ insulin for $48 \mathrm{~h}$, and cell lysates were subjected to western blotting. The protein level of (A) insulin receptor (IR) and insulin receptor substrates 1 (IRS-1), as well as (B) p-PI3K (Tyr458), PI3K, p-Akt (Ser473) and Akt, was detected and adjusted for equivalent loading using the $\beta$-actin protein level.

showing that IR functionally enhances pro-tumorigenic signals in HCT-116 cells.

Insulin regulates downstream PI3K/Akt signaling in HCT-116 cells. To determine whether the downstream signals are involved in the regulation of insulin-treated HCT-116 cells through the PI3K/Akt signaling pathway, we further tested the protein levels of mTOR, GSK $3 \beta$ and p53 to specifically clarify the functional regulation. Insulin treatment induced the phosphorylation of mTOR (Ser2448) (Fig. 3A) and GSK3 $\beta$ (Ser9) (Fig. 3B). In addition, treatment with insulin induced the p53 level in a concentration-dependent manner in treated cells (Fig. 3C). These results demonstrate that the enhancement of insulin-induced IR signaling was observed via the PI3K/Akt pathway by activation of $\mathrm{mTOR} / \mathrm{GSK} 3 \beta$, an activity that was not due to the suppression of the p53 signal in HCT-116 cells.

Insulin affects cell cycle-associated protein expression of c-Myc and cyclin D1, as well as HSP27 in HCT-116 cells. Our results have shown that insulin increased HCT-116 cell proliferation (Fig. 1). To verify whether c-Myc and cyclin D1 are involved in insulin-induced HCT-116 cell proliferation, we examined the levels of c-Myc and cyclin D1 by western blot analysis. Insulin increased the cyclin D1 level, but it decreased c-Myc protein expression in HCT-116 cells (Fig. 4A). It seems that insulin stimulated cell proliferation through regulating c-Myc and cyclin D1 levels in HCT-116 cells. To further detect whether insulin causes the translocation of HSP27 and c-Myc, we further analyzed the protein expression of c-Myc and HSP27 in nuclear and cytosolic fractions, respectively.
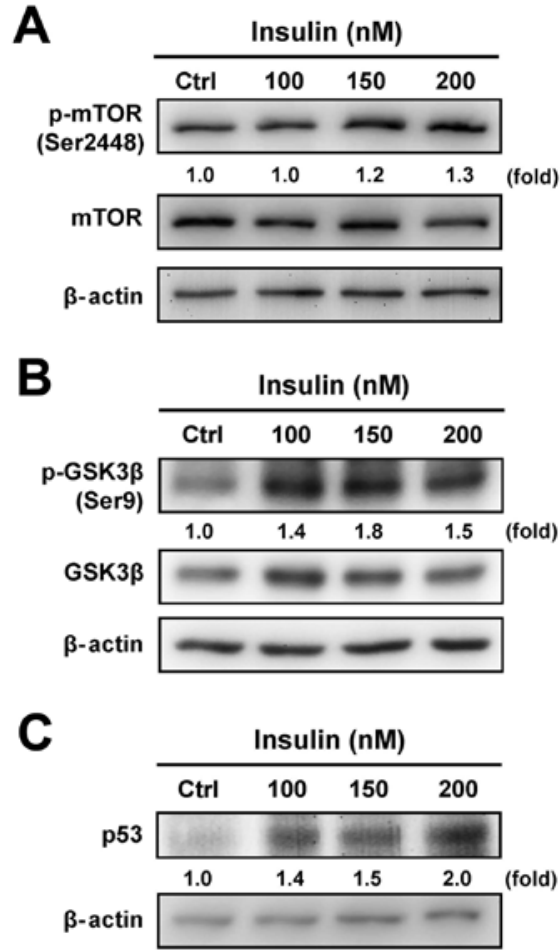

Figure 3. Effect of insulin downstream of PI3K/Akt signaling of HCT-116 cells. Cells were incubated with different concentrations $(100,150$ and $200 \mathrm{nM}$ ) of insulin for $48 \mathrm{~h}$. Whole-cell lysates were extracted for the detection of the protein levels of (A) p-mTOR (Ser2448) and mTOR, (B) p-GSK3 $\beta$ (Ser9) and GSK3 $\beta$, and (C) p53 by immunoblotting. $\beta$-actin served as an internal control.
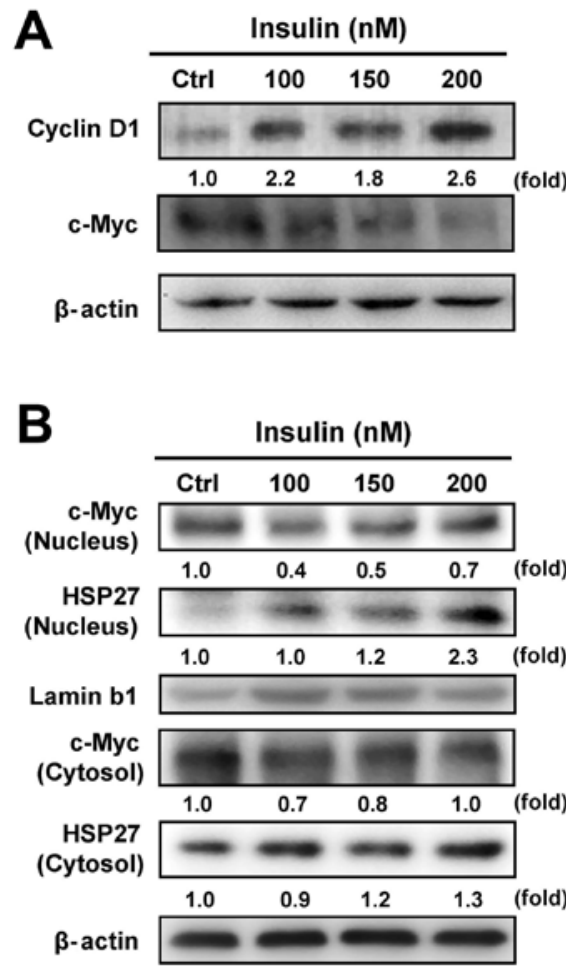

Figure 4. Effect of insulin on the protein levels of c-Myc, cyclin D1 and HSP27 in HCT-116 cells. Cells were treated with 100, 150 and $200 \mathrm{nM}$ insulin for $48 \mathrm{~h}$. (A) Total cell lysates were submitted to cyclin D1 and c-Myc by western blot analysis. (B) The nuclear and cytosolic fractions were prepared, and immunoblot analysis showed the expression levels of c-Myc and HSP27 in cells. Lamin B1 was used for nuclear loading control, and each protein level was normalized relative to the $\beta$-actin protein level. 
A

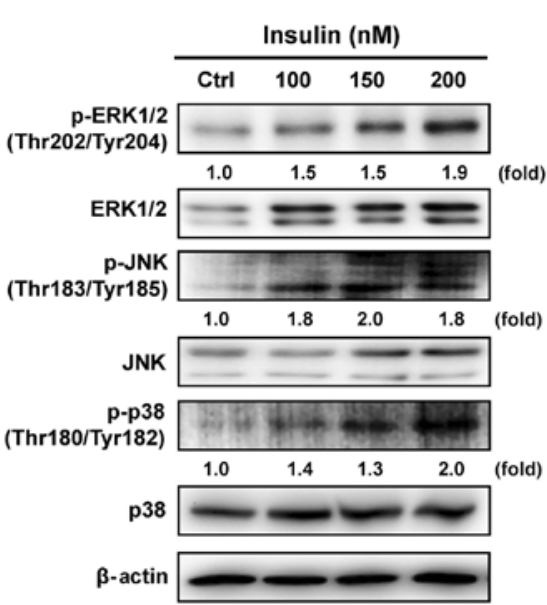

B

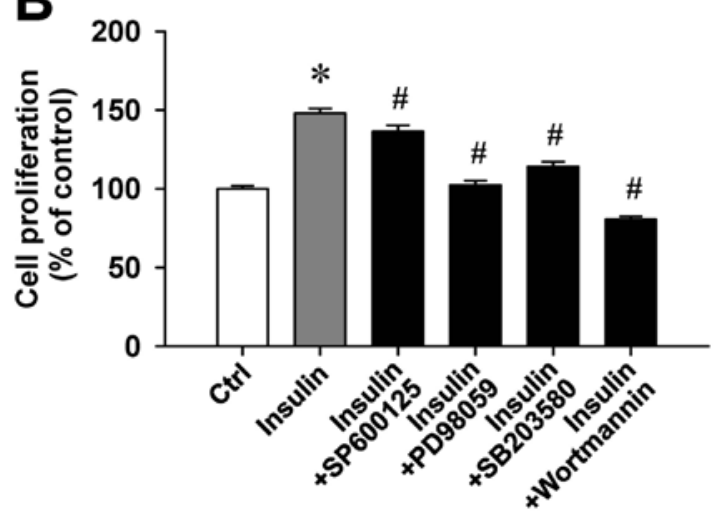

Figure 5. Effect of insulin on MAPK signaling and their specific inhibitors in HCT-116 cells. (A) Cells were incubated with 100, 150 and $200 \mathrm{nM}$ insulin for $48 \mathrm{~h}$ and then were harvested to measure the indicated protein levels [p-ERK1/2 (Thr202/Tyr204), ERK1/2, p-JNK (Thr183/Tyr185), JNK, p-p38 (Thr180/Tyr182) and p38] by western blotting. $\beta$-actin served as the loading control. (B) After individual pretreatment with $20 \mu \mathrm{M}$ SP600125, PD98059, SB203580 and wortmannin, exposure to insulin for $48 \mathrm{~h}$ was determined by the trypan blue exclusion assay. The data are expressed as the mean $\pm \mathrm{SD}$ $(\mathrm{n}=3) .{ }^{*} \mathrm{P}<0.05$ vs. untreated control; ${ }^{~} \mathrm{P}<0.05$ vs. only insulin-treated cells.

We observed a decrease in c-Myc nuclear translocation and an increase in HSP27 trafficking into the nucleus of HCT-116 cells after insulin exposure, while insulin attenuated cytosolic c-Myc and enhanced HSP27 in the cytosol (Fig. 4B). These data implied that the activity of c-Myc and HSP27 might be required in insulin-induced HCT-116 cell proliferation.

Insulin enhances MAPK signaling in HCT-116 cells. To examine whether cell proliferation in response to insulin challenge is associated with the MAPK pathway, we determined the level of MAPK (ERK, JNK and p38) molecules in insulin-treated HCT-116 cells. Insulin challenge resulted in an upregulation of phosphorylated MAPK-associated protein levels, including the phosphorylation of ERK1/2 on Thr202/ Tyr204, JNK on Thr183/Tyr185 and p38 on Thr180/Tyr182 (Fig. 5A). To confirm the roles of MAPK-triggered cell proliferation by insulin, we individually pretreated HCT-116 cells with or without SP600125 (a JNK-specific inhibitor), PD98059 (an ERK-specific inhibitor), SB203580 (a p38-specific inhibitor) or wortmannin (a PI3K-specific inhibitor) before exposure to insulin to investigate cell viability. These four inhibitors were effective on the inhibition of insulin-enhanced
A
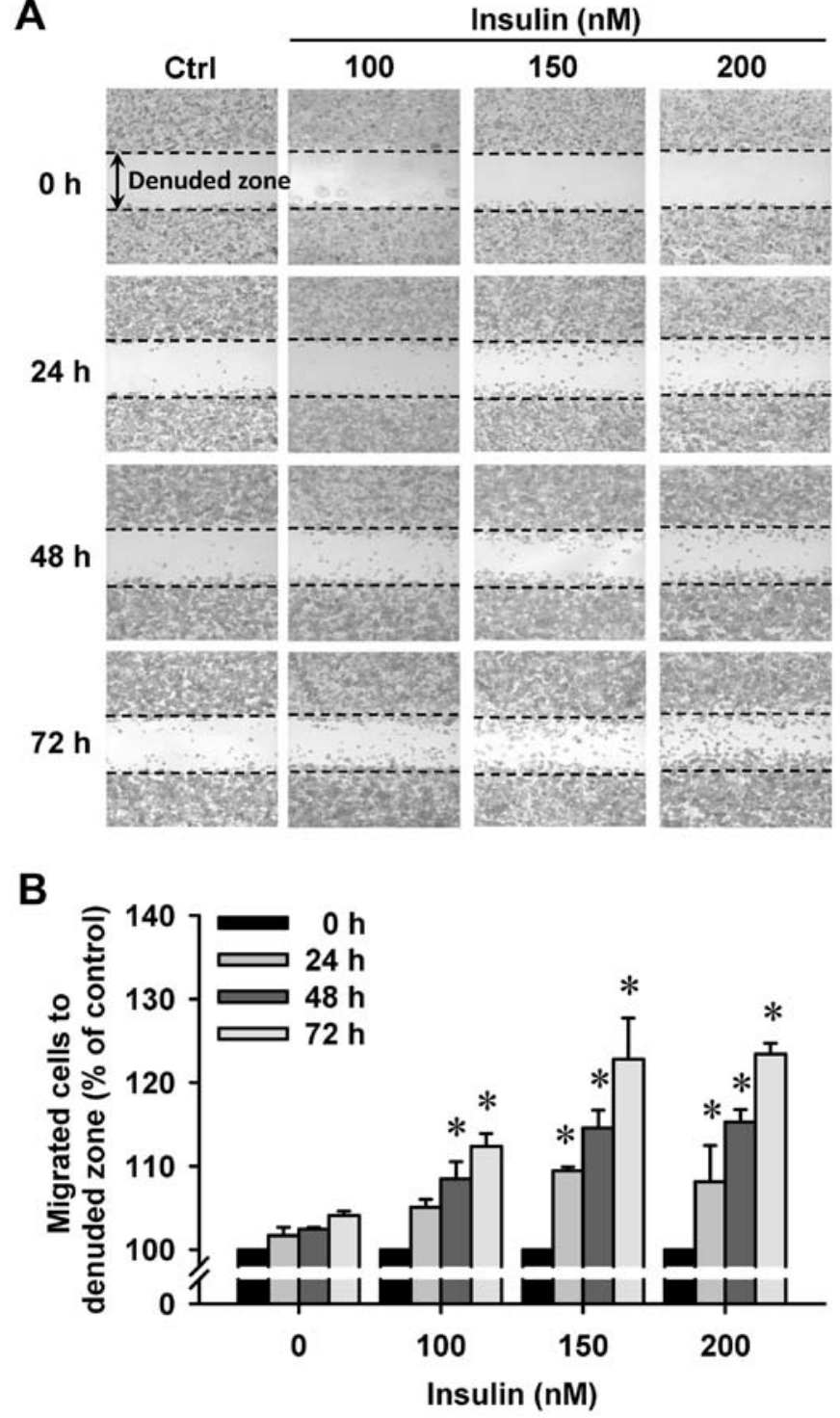

Figure 6. Effect of insulin on motility of HCT-116 cells. Confluent monolayers of cells were wounded before incubation with 100, 150 and $200 \mathrm{nM}$ of insulin for indicated periods of time. (A) The relative denuded zone (wound closures) and migrated cells were examined and photographed. (B) The migrated cells were monitored and quantified. The data are expressed as the mean $\pm \mathrm{SD}(\mathrm{n}=3)$. ${ }^{*} \mathrm{P}<0.05$ vs. untreated control.

cell proliferation (Fig. 5B). Specifically, PD98059 and wortmannin significantly attenuated insulin-induced viability by up to $45.5 \%$ and $67.4 \%$, respectively, compared with insulin treatment alone. Therefore, we provide bimolecular evidence regarding the influence of MAPK and PI3K signaling that contribute to insulin-provoked proliferation in HCT-116 cells.

Insulin promotes HCT-116 cell motility and migration in vitro. We then further investigated whether insulin has an impact on cell migration in HCT-116 cells by the wound-healing assay. Insulin treatment significantly enhanced cell migration to the denuded zone (Fig. 6A) and stimulated cell motility in a timeand concentration-dependent manner (Fig. 6B). After $48 \mathrm{~h}$ of insulin exposure, the cells on the lower surface of the filter were examined under a microscope in HCT-116 cells. Insulin markedly elicited the number of migrated cells as measured by the Transwell migration assay at $48 \mathrm{~h}$ after insulin treatment 
A
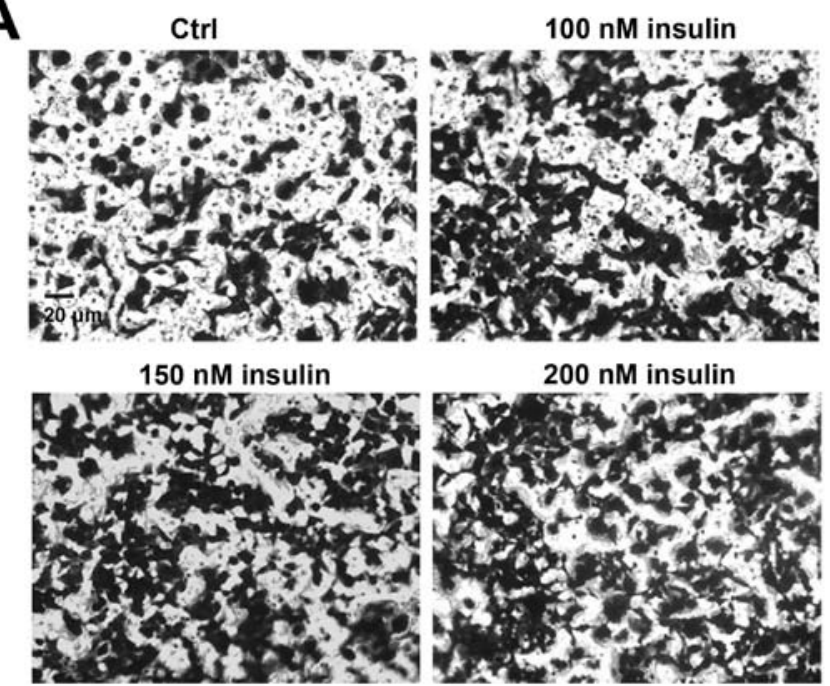

B

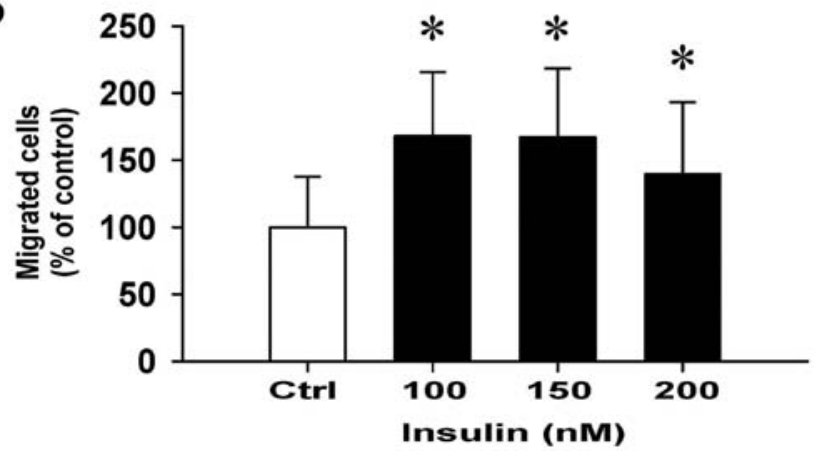

Figure 7. Effect of insulin on migration of HCT-116 cells. Cells were seeded in the upper chamber of the Transwell insert and exposed to insulin $(100,150$ and $200 \mathrm{nM}$ ). (A) After a 48-h incubation, cells migrating to lower side of the membrane were stained and subsequently photographed. Scale bar, $20 \mu \mathrm{m}$. (B) Quantitative results of migrated cells were measured, and the data are expressed as the mean $\pm \mathrm{SD}(\mathrm{n}=3)$. ${ }^{*} \mathrm{P}<0.05$ vs. untreated control.

(Fig. 7A). The migration ability was increased by insulin treatment of (Fig. 7B). These findings demonstrate that insulin promoted the migration ability of HCT-116 cells.

Insulin upregulates gene expression and gelatinolytic activity of MMP-2 in HCT-116 cells. To clarify whether insulin regulates the secretion of MMP-2 by HCT-116 cells, we employed RT-PCR and gelatin zymography assays. There was a noticeable induction in MMP-2 gene expression after insulin treatment at 150 and $200 \mathrm{nM}$ for $48 \mathrm{~h}$ (Fig. 8A). However, insulin had no effect on the MMP-9 mRNA level in treated cells (Fig. 8A). In addition, a gelatinolytic band corresponding to MMP-2 was significantly increased by insulin in the culture medium that was stimulated, and quantitative analysis of these results was performed to show that enzymatic activity of MMP-2 was increased in HCT-116 cells (Fig. 8B). Based on the data, insulin leads to cell migration through increasing the MMP-2 levels in HCT-116 cells.

\section{Discussion}

Diabetes is a systemic metabolic disorder caused by defects in insulin secretion and insulin activity, resulting in patients

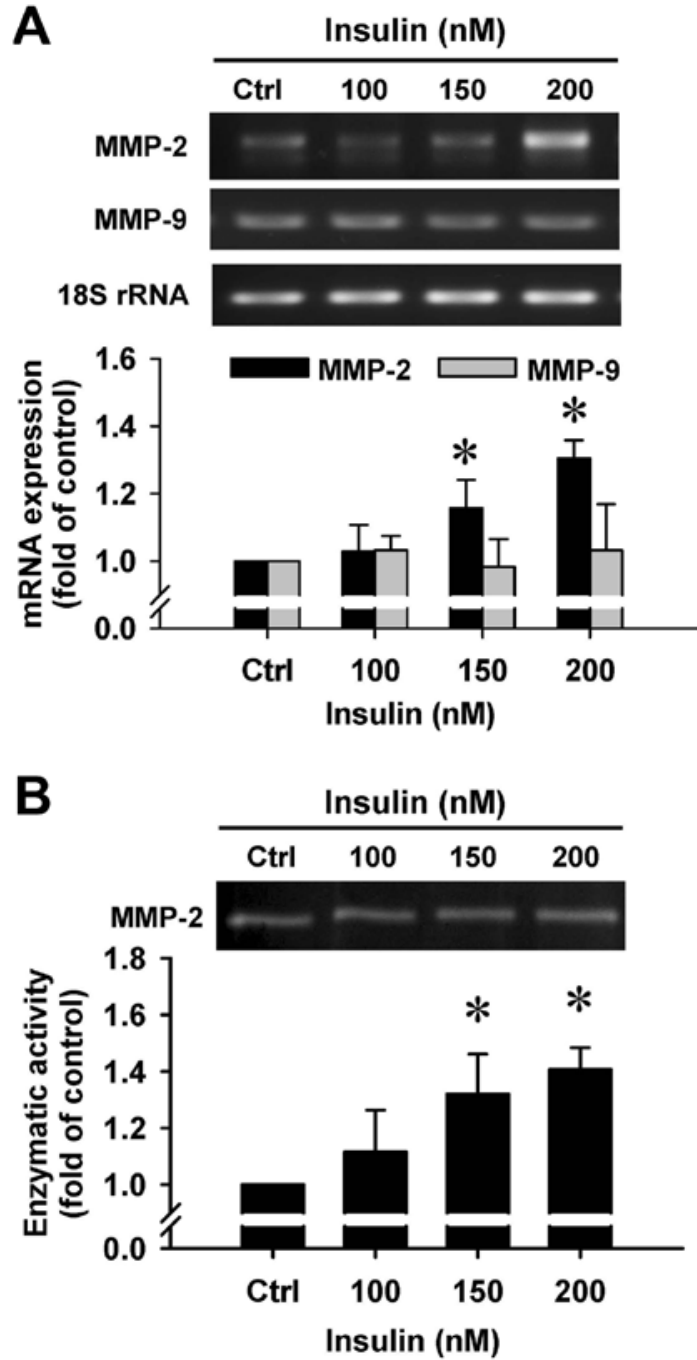

Figure 8. Effect of insulin on the gene expression and enzymatic activity of matrix metalloproteinase-2 (MMP-2) in HCT-116 cells. Cells were incubated with 100,150 and $200 \mathrm{nM}$ of insulin for $48 \mathrm{~h}$ and then individually subjected to (A) RT-PCR and (B) gelatin zymography assay, as described in Materials and methods. The gene expression of MMP-2 and MMP-9, as well as MMP-2 enzymatic activity were performed and quantified. The data are expressed as the mean $\pm \mathrm{SD}(\mathrm{n}=3)$. ${ }^{*} \mathrm{P}<0.05$ vs. untreated control.

with abnormal carbohydrate metabolism inducing hyperglycemia and hyperinsulinemia, which are the major causes of the systemic inflammatory response $(2,24)$. It has been noted that the recurrence rate and mortality of patients were substantially increased with the coexistence of diabetes and some cancers $(10,25)$. Regarding the lack of insulin, tumor cell growth cannot directly be promoted in diabetes patients with hyperglycemia (9). However, the high concentration of insulin has been reported to activate IR signaling to enhance tumor growth, which acts an important mediator $(15,26)$. Currently, the mortality of patients with diabetes and colorectal cancer is higher than that in patients with colorectal cancer only; among them, the patients with type 2 diabetes possess a higher risk of colorectal cancer $(12,27,28)$. Therefore, this study focused on exploring the effect of insulin on colorectal cancer cell proliferation and migration, as well as clarifying the underlying molecular mechanism in human colorectal cancer cells in vitro. 
In this study, the human colon cancer cell line HCT-116 was used to assess the effects of different concentrations of insulin on the cytotoxicity of the tumor cells. A previous study has shown that insulin treatment at $100 \mathrm{nM}$ interacted with optimal defensing expression (29) and was involved in $\beta$-cell function during fasting plasma insulin concentrations in man (30). We found that insulin at 100-300 $\mathrm{nM}$ had no significant cytotoxic effect and exhibited an increase in cell proliferation in HCT-116 cells (Fig. 1), agreeing with that in a previously published study (31). In addition, the process of attached cell adhesion to the extracellular matrix (ECM) is critical during cancer cell proliferation and progression. The transformation of cancer cells may be dependent on the behavior of continued growth, which can serve as an important clue for the malignant progression of cancer (32).

We further investigated the impact of insulin on anchorageindependent cancer cell growth. Our findings demonstrate that insulin significantly increased cell proliferation and markedly promoted the growth of cancer cells by the poly-HEMA coated assay to prevent cell attachment (Fig. 1B). Moreover, for long-term analysis (7 days), there was a similar effect on HCT-116 cell proliferation (data not shown). Previous studies have shown that mitogenic and oncogenic stimulation enhance tumor cell growth and alter protein kinase activity and nuclear localization $(19,33)$. Thus, it can be speculated that insulin promotes the characteristics of cancer cell proliferation to stimulate cancer progression in HCT-116 cells.

Insulin might play a vital role in the patients with diabetes and cancer progression (34). Increasing evidence has suggested that the activation of IR signaling is mediated through the binding of insulin and IR to cause cancer cell survival and mitotic actions (10). It has been recognized that the activation of insulin signaling stimulates IRS-1 to further affect the PI3K/Akt pathway and to induce ERK phosphorylation, finally leading to cancer cell survival and mitotic effects (35-37). Our data showed that insulin increased the levels of IR and IRS-1 expression in HCT-116 cells (Fig. 2), a finding that agrees with a previously published study regarding insulin enhancing IR expression and then dramatically altering the downstream signaling pathway in breast cancer LCC6 cells (36). Therefore, we suggest that it is unnecessary that a dramatic increase in the IR signal caused by insulin occurs, but their downstream proteins are important after IR activation in colon cancer cells.

Many studies have provided consistent evidence that the phosphorylation of PI3K/Akt and ERK signaling can be upregulated upon insulin pathway activation $(36,38)$. Our experimental results showed that the induction of the protein levels of phosphorylated PI3K/Akt and ERK signals was observed in insulin-treated HCT-116 cells (Figs. 2B and 5A). In addition, insulin increased the phosphorylated proteins of JNK and p38 MAPKs in the examined cells (Fig. 5A). Importantly, preincubation with MAPK inhibitors (SP600125, PD98059 and SB203580) after insulin exposure diminished HCT cell proliferation (Fig. 5B). Therefore, the event of the MAPK signaling response for cell proliferation requires the accumulation of insulin in human colorectal cancer cells. Furthermore, the roles of the PI3K/Akt pathway and its downstream signaling are vital during cancer progression (39). For example, the mTOR signal is involved in cell proliferation; GSK3 $\beta$ can regulate the cell cycle-associated proteins (c-Myc and cyclin D1); p53 can alter the effect of apoptosis and cell cycle-related signals (39). It has been reported that mRNA transcription, cell growth and cell proliferation can modulate the phosphorylation of mTOR by activating the PI3K/Akt/ mTOR pathway $(40,41)$.

Our current study provides information that the insulinpromoted cell proliferation occurred partly through mTOR signaling (Fig. 3A), indicating that mTOR signaling is a minor mediator, and the other crucial regulators might exist in insulin-treated HCT-116 cells. It was reported that the activation of $\mathrm{PI} 3 \mathrm{~K} / \mathrm{Akt} / \mathrm{GSK} 3 \beta$ signaling promotes the phosphorylated GSK $3 \beta$ on Ser9 to increase cyclin D1 expression, which accelerates the entry from G1 phase into $\mathrm{S}$ phase $(42,43)$. Our results clearly showed that insulin significantly increased phosphorylated GSK3 $\beta$ (Ser9) (Fig. 3B) and cyclin D1 (Fig. 4A) in HCT-116 cells, suggesting that insulin activated the Akt signal to phosphorylate GSK3 $\beta$ following the induction of cell proliferation through increasing cyclin D1 expression, an activity that is required for cell cycle progression. Furthermore, the growth factors can suppress p53 expression through stimulating PI3K/Akt signaling to promote cell cycle progression. However, the regulation of PTEN expression by p53 can inhibit Akt activation (44). In the present study, our results showed that insulin treatment markedly promoted p53 expression in HCT-116 cells (Fig. 3C). A previous study demonstrated that the p53-dependent effect contributing to the proliferation in uterine serous carcinoma USPC-1 cells carrying wild-type p53 was induced by metformin through the downregulation of insulin/IGF-1 signaling (45). These results suggest that the insulin-stimulated Akt signal could not suppress p53 expression due to HCT-116 cells carrying wildtype p53 (46), creating a feedback effect to reach the balance of dramatic cell proliferation caused by insulin.

MAPK family members can regulate cell proliferation, cell differentiation and cancer progression and play vital roles in cell apoptosis $(47,48)$. Insulin signaling induces cell proliferation through the activation of the ERK/MAPK pathway, and the JNK and p38 MAPK had similar effects $(36,38)$. Our findings showed that insulin significantly increased the phosphorylation of ERK, JNK and p38 MAPKs in HCT-116 cells (Fig. 5A). Additionally, it is well known that HSP27 and the transcription factor c-Myc are regulated by MAPK signaling $(47,49)$. We found that the transcription factor c-Myc was decreased in the nuclear fraction, but HSP27 was translocated to the nucleus in cells after insulin challenge (Fig. 4B). This finding is also in agreement with other reports showing that MAPK signaling can modulate c-Myc expression, and the cancer cell invasive ability can be regulated by p38 MAPK $(47,49)$.

Based on our functional study, it was demonstrated that insulin triggered cell proliferation and metastatic effects through MAPK signaling, as well as decreasing c-Myc expression and increasing HSP27 signaling in HCT-116 cells. Evidence has shown that the function of the oncogene c-Myc exhibits stimulated cell proliferation and apoptosis, and cyclin D1 can drive cell cycle progression and acts on cell growth to integrate the cell cycle machinery $(42,50)$. Our results revealed that insulin increased the amount of cyclin D1 expression and reduced the protein levels of c-Myc expression (Fig. 4A), suggesting that cancer cell apoptosis was evaded by insulin and showed a high ability of drug resistance (50). 
Cancer cell metastasis has been shown to be involved in the vital events of the intercellular degradation of the extracellular matrix, invasion and migration ability during tumor progression $(22,51)$. Furthermore, chronic hyperinsulinemia promotes primary tumor growth and the progression to lung metastasis in a mouse model of type 2 diabetes. We further investigated the effect of insulin on the metastatic effects of HCT-116 cells. Our data demonstrated that insulin enhanced HCT-116 cell migration, and MMP-2 might be involved in the metastatic process caused by insulin (Figs. 6-8), eventually leading to cancer cell progression. This finding is also in agreement with the report by Qi et al (52), proving that insulin/protein kinase B signaling upregulates metastasis-related phenotypes and molecules in human hepatocarcinoma cells.

In conclusion, our study showed, for the first time, that insulin triggers cell proliferation and the induction of metastatic effects on human colorectal cancer HCT-116 cells that is modulated by IR signaling and the PI3K/Akt/GSK3 $\beta$ pathway as well as MMP-2 regulation. We report a concept and insight addressing how insulin interacts with cell proliferation and migration in colon cancer cells. Therefore, these data support our hypothesis and offer an approach for insulin induction. The existing evidence indicates that colorectal cancer progression might be involved in insulin induction, and diabetes patients might need to pay close attention to this issue.

\section{Acknowledgements}

This work was supported in part by the Ministry of Education, Taiwan, under the ATU plan and in part by the grant MOST1032313-B-038-003-MY3 from the Ministry of Science and Technology, Taiwan.

\section{References}

1. Zimmet P, Alberti KG and Shaw J: Global and societal implications of the diabetes epidemic. Nature 414: 782-787, 2001.

2. Tsai TY, Cheng JF and Lai YM: Prevalence of metabolic syndrome and related factors in Taiwanese high-tech industry workers. Clinics (Sao Paulo) 66: 1531-1535, 2011.

3. Maria Rotella C, Pala L and Mannucci E: Role of insulin in the type 2 diabetes therapy: Past, present and future. Int J Endocrinol Metab 11: 137-144, 2013.

4. Krone CA and Ely JT: Controlling hyperglycemia as an adjunct to cancer therapy. Integr Cancer Ther 4: 25-31, 2005.

5. Stattin P, Björ O, Ferrari P, Lukanova A, Lenner P, Lindahl B, Hallmans G and Kaaks R: Prospective study of hyperglycemia and cancer risk. Diabetes Care 30: 561-567, 2007.

6. Hsieh MC, Lee TC, Cheng SM, Tu ST, Yen MH and Tseng CH: The influence of type 2 diabetes and glucose-lowering therapies on cancer risk in the Taiwanese. Exp Diabetes Res 2012: 413782, 2012.

7. Beckner ME, Stracke ML, Liotta LA and Schiffmann E: Glycolysis as primary energy source in tumor cell chemotaxis. J Natl Cancer Inst 82: 1836-1840, 1990.

8. Heuson JC and Legros N: Influence of insulin deprivation on growth of the 7,12-dimethylbenz(a)anthracene-induced mammary carcinoma in rats subjected to alloxan diabetes and food restriction. Cancer Res 32: 226-232, 1972.

9. Masur K, Vetter C, Hinz A, Tomas N, Henrich H, Niggemann B and Zänker KS: Diabetogenic glucose and insulin concentrations modulate transcriptome and protein levels involved in tumour cell migration, adhesion and proliferation. Br J Cancer 104: $345-352,2011$

10. Giovannucci E, Harlan DM, Archer MC, Bergenstal RM, Gapstur SM, Habel LA, Pollak M, Regensteiner JG and Yee D: Diabetes and cancer: A consensus report. CA Cancer J Clin 60: 207-221, 2010.
11. Will JC, Galuska DA, Vinicor F and Calle EE: Colorectal cancer: Another complication of diabetes mellitus? Am J Epidemiol 147: 816-825, 1998

12. Saydah SH, Platz EA, Rifai N, Pollak MN, Brancati FL and Helzlsouer KJ: Association of markers of insulin and glucose control with subsequent colorectal cancer risk. Cancer Epidemiol Biomarkers Prev 12: 412-418, 2003.

13. Giovannucci E: Insulin, insulin-like growth factors and colon cancer: A review of the evidence. J Nutr 131 (Suppl): 3109S-3120S, 2001.

14. Zhang H, Pelzer AM, Kiang DT and Yee D: Down-regulation of type I insulin-like growth factor receptor increases sensitivity of breast cancer cells to insulin. Cancer Res 67: 391-397, 2007.

15. Dinchuk JE, Cao C, Huang F, Reeves KA, Wang J, Myers F, Cantor GH,Zhou X, Attar RM, Gottardis M, et al: Insulin receptor (IR) pathway hyperactivity in IGF-IR null cells and suppression of downstream growth signaling using the dual IGF-IR/IR inhibitor, BMS-754807. Endocrinology 151: 4123-4132, 2010.

16. Guo H, Gao M, Lu Y, Liang J, Lorenzi PL, Bai S, Hawke DH, Li J, Dogruluk T, Scott KL, et al: Coordinate phosphorylation of multiple residues on single AKT1 and AKT2 molecules. Oncogene 33: 3463-3472, 2014.

17. Ericson K, Gan C, Cheong I, Rago C, Samuels Y, Velculescu VE, Kinzler KW, Huso DL, Vogelstein B and Papadopoulos N: Genetic inactivation of AKT1, AKT2, and PDPK1 in human colorectal cancer cells clarifies their roles in tumor growth regulation. Proc Natl Acad Sci USA 107: 2598-2603, 2010.

18. Strober W: Trypan blue exclusion test of cell viability. Curr Protoc Immunol 111: A3.B.1-3, 2015.

19. Fukazawa H, Mizuno S and Uehara Y: A microplate assay for quantitation of anchorage-independent growth of transformed cells. Anal Biochem 228: 83-90, 1995.

20. Folkman J and Moscona A: Role of cell shape in growth control. Nature 273: 345-349, 1978.

21. Lu CC, Yang SH, Hsia SM, Wu CH and Yen GC: Inhibitory effects of Phyllanthus emblica L. on hepatic steatosis and liver fibrosis in vitro. J Funct Foods 20: 20-30, 2016.

22. Lu CC, Yang JS, Chiang JH, Hour MJ, Amagaya S, Lu KW, Lin JP, Tang NY, Lee TH and Chung JG: Inhibition of invasion and migration by newly synthesized quinazolinone MJ-29 in human oral cancer CAL 27 cells through suppression of MMP-2/9 expression and combined down-regulation of MAPK and AKT signaling. Anticancer Res 32: 2895-2903, 2012.

23. Lu CC, Yang JS, Huang AC, Hsia TC, Chou ST, Kuo CL, Lu HF, Lee TH, Wood WG and Chung JG: Chrysophanol induces necrosis through the production of ROS and alteration of ATP levels in J5 human liver cancer cells. Mol Nutr Food Res 54: 967-976, 2010.

24. Kitabchi AE, Umpierrez GE, Miles JM and Fisher JN: Hyperglycemic crises in adult patients with diabetes. Diabetes Care 32: 1335-1343, 2009.

25. Barone BB, Yeh HC, Snyder CF, Peairs KS, Stein KB, Derr RL, Wolff AC and Brancati FL: Long-term all-cause mortality in cancer patients with preexisting diabetes mellitus: A systematic review and meta-analysis. JAMA 300: 2754-2764, 2008.

26. Lawlor MA and Alessi DR: PKB/Akt: A key mediator of cell proliferation, survival and insulin responses? J Cell Sci 114: 2903-2910, 2001.

27. Le Marchand L, Wilkens LR, Kolonel LN, Hankin JH and Lyu LC: Associations of sedentary lifestyle, obesity, smoking, alcohol use, and diabetes with the risk of colorectal cancer. Cancer Res 57: 4787-4794, 1997.

28. Kono S, Honjo S, Todoroki I, Nishiwaki M, Hamada $\mathrm{H}$, Nishikawa H, Koga H, Ogawa S and Nakagawa K: Glucose intolerance and adenomas of the sigmoid colon in Japanese men (Japan). Cancer Causes Control 9: 441-446, 1998.

29. Barnea M, Madar Z and Froy O: Glucose and insulin are needed for optimal defensin expression in human cell lines. Biochem Biophys Res Commun 367: 452-456, 2008.

30. Matthews DR, Hosker JP, Rudenski AS, Naylor BA, Treacher DF and Turner RC: Homeostasis model assessment: Insulin resistance and beta-cell function from fasting plasma glucose and insulin concentrations in man. Diabetologia 28: 412-419, 1985.

31. Ayiomamitis GD, Notas G, Zaravinos A, Drygiannakis I, Georgiadou M, Sfakianaki O, Mastrodimou N, Thermos K and Kouroumalis E: Effects of octreotide and insulin on colon cancer cellular proliferation and correlation with hTERT activity. Oncoscience 1: 457-467, 2014. 
32. DeBerardinis RJ, Lum JJ, Hatzivassiliou G and Thompson CB The biology of cancer: Metabolic reprogramming fuels cell growth and proliferation. Cell Metab 7: 11-20, 2008

33. Lv L, Xu YP, Zhao D, Li FL, Wang W, Sasaki N, Jiang Y, Zhou X, Li TT, Guan KL, et al: Mitogenic and oncogenic stimulation of K433 acetylation promotes PKM2 protein kinase activity and nuclear localization. Mol Cell 52: 340-352, 2013.

34. Duan W, Shen X, Lei J, Xu Q, Yu Y, Li R, Wu E and Ma Q: Hyperglycemia, a neglected factor during cancer progression. BioMed Res Int 2014: 461917, 2014.

35. Saltiel AR and Pessin JE: Insulin signaling pathways in time and space. Trends Cell Biol 12: 65-71, 2002.

36. Zhang H, Fagan DH, Zeng X, Freeman KT, Sachdev D and Yee D: Inhibition of cancer cell proliferation and metastasis by insulin receptor downregulation. Oncogene 29: 2517-2527, 2010.

37. Lau MT and Leung PC: The PI3K/Akt/mTOR signaling pathway mediates insulin-like growth factor 1-induced E-cadherin downregulation and cell proliferation in ovarian cancer cells. Cancer Lett 326: 191-198, 2012.

38. Ulanet DB, Ludwig DL, Kahn CR and Hanahan D: Insulin receptor functionally enhances multistage tumor progression and conveys intrinsic resistance to IGF-1R targeted therapy. Proc Natl Acad Sci USA 107: 10791-10798, 2010.

39. Jiang BH and Liu LZ: PI3K/PTEN signaling in tumorigenesis and angiogenesis. Biochim Biophys Acta 1784: 150-158, 2008.

40. Dancey J: mTOR signaling and drug development in cancer. Nat Rev Clin Oncol 7: 209-219, 2010.

41. Laplante M and Sabatini DM: mTOR signaling in growth control and disease. Cell 149: 274-293, 2012.

42. Yang K, Guo Y, Stacey WC, Harwalkar J, Fretthold J, Hitomi M and Stacey DW: Glycogen synthase kinase 3 has a limited role in cell cycle regulation of cyclin D1 levels. BMC Cell Biol 7: 33 , 2006.

43. Takahashi-Yanaga $\mathrm{F}$ and Sasaguri T: GSK-3beta regulates cyclin D1 expression: A new target for chemotherapy. Cell Signal 20: 581-589, 2008 .
44. Maddocks OD and Vousden KH: Metabolic regulation by $\mathrm{p} 53$. J Mol Med (Berl) 89: 237-245, 2011.

45. Sarfstein R, Friedman Y, Attias-Geva Z, Fishman A, Bruchim I and Werner H: Metformin downregulates the insulin/IGF-I signaling pathway and inhibits different uterine serous carcinoma (USC) cells proliferation and migration in p53-dependent or -independent manners. PLoS One 8: e61537, 2013.

46. Zawacka-Pankau J, Issaeva N, Hossain S, Pramanik A, Selivanova G and Podhajska AJ: Protoporphyrin IX interacts with wild-type p53 protein in vitro and induces cell death of human colon cancer cells in a p53-dependent and -independent manner. J Biol Chem 282: 2466-2472, 2007.

47. Zhang W and Liu HT: MAPK signal pathways in the regulation of cell proliferation in mammalian cells. Cell Res 12: 9-18, 2002.

48. Wada T and Penninger JM: Mitogen-activated protein kinases in apoptosis regulation. Oncogene 23: 2838-2849, 2004.

49. Huang C, Jacobson K and Schaller MD: MAP kinases and cell migration. J Cell Sci 117: 4619-4628, 2004.

50. Liao DJ, Thakur A, Wu J, Biliran H and Sarkar FH: Perspectives on c-Myc, Cyclin D1, and their interaction in cancer formation, progression, and response to chemotherapy. Crit Rev Oncog 13: 93-158, 2007.

51. Lu Z, Lu N, Li C, Li F, Zhao K, Lin B and Guo Q: Oroxylin A inhibits matrix metalloproteinase-2/9 expression and activation by up-regulating tissue inhibitor of metalloproteinase- 2 and suppressing the ERK1/2 signaling pathway. Toxicol Lett 209: 211-220, 2012.

52. Qi HL, Zhang Y, Ma J, Guo P, Zhang XY and Chen HL: Insulin/protein kinase B signalling pathway upregulates metastasis-related phenotypes and molecules in H7721 human hepatocarcinoma cell line. Eur J Biochem 270: 3795-3805, 2003. 